\title{
Usando a Criatividade Literária em Ambiente Formal: Contextos de uma
} Educação Híbrida

\section{Using Literary Creativity in Formal Environment: Contexts of a Hybrid Education}

\author{
Ana Calixto \\ Universidade do Minho
}

\begin{abstract}
Resumo
Este trabalho apresenta uma investigação de análise do uso do software Storybord, sob a perspectiva das aprendizagens colaborativas vivenciadas em contexto de ensino híbrido, modelo flex de aprendizagem, idealizado por Horn \& Staker (2015). A obter mais-valias das produções acerca da escrita criativa, que advém das práticas escolares, por meio de ferramentas, digitais e comunicacionais, visou-se observar efeitos no processo de utilização dessa interface pelos sujeitos-receptores envolvidos nessa ação. A teorização ancora-se na importância da literacia digital na escola e liberdade do pensamento criativo. Sobretudo, a relevância dessa aprendizagem recai sobre o protagonismo dos alunos de educação básica.

Palavras-chave: Ensino Híbrido,Tecnologia Educativa, imaginário infantil, Storybird, literacia digital
\end{abstract}

\begin{abstract}
This paper presents an investigation of the use of Storybord software, from the perspective of collaborative learning in the context of hybrid teaching, a flex learning model, idealized by Horn \& Staker (2015). In order to obtain gains in creative writing, which comes from the school practices, through tools, digital and communication, it was aimed to observe effects in the process of using this interface by the subjects involved in this action. Theorization anchors the importance of digital literacy in school and freedom of creative thinking. Above all, the relevance of this learning rests on the protagonism of the students of basic education. Creative writing, Educational Technology, collaborative learning, hybrid teaching, formal education.

Keywords: Creative writing, Educational Technology, collaborative learning, hybrid teaching, formal education
\end{abstract}

\section{Introdução}

O ciberespaço tem sido consolidado como um ambiente muito frequentado e bem explorado por grande parte dos seres humanos. No entanto, ainda não vemos no veículo online, o explorar de o dinamismo das suas potencialidades do ponto de vista didático-pedagógico. Acredita-se, todavia, na construção do conhecimento em ambiente formal de contexto hibrido e no aprimoramento da inclusão tecnológica como pontos centrais de superação desta realidade, reforçando neste sentido a necessária exploração da literacia digital neste meio.
Relativamente ao que foi inicialmente justificado, a investigação do qual decorre esse artigo teve como principal finalidade o exercício digital da escrita alfabética e leitura coletiva em uma prática de ensino híbrido, de modo a perceber o atual panorama e o possível alcance do hipertexto, diante do desenvolvimento das práticas virtuais em contexto letivo diferente do habitual. Acredita-se em um ambiente transformador, pois o mundo imaginário existente na mente da criança é surpreendente e aliado a um bom trabalho institucional, os resultados poderão ser reveladores. Portanto o projeto teve como objetivo prioritário aplicar ensino hibrido em ambiente formal (escola) de moda a desenvolver a literacia digital, por meios da literatura de contos infantis, em alunos do $3^{\circ}$ ano do $1^{\circ}$ ciclo, através de leituras e escritas virtuais de narrativas com o suporte do software de aprendizagem, Storybird.

Busca-se assim, analisar se a ferramenta tecnológica introduzida por essa interface trará progressos à compreensão e produção leitora em diferentes situações comunicativas de aprendizagem. Contudo, nos é pertinente observar se o trabalho motivará a mistura de linguagens, ou seja, se acolherá o uso das convergências mediáticas envolvendo-se com diferentes códigos semânticos e ainda com a tradicional língua falada e escrita, para que assim tenhamos a prática do ensino híbrido no processo de ensino - aprendizagem. Com a expectativa de que o aluno poderá ser conduzido a um caminho lúdico, rico em descobertas e trocas de novos conhecimentos, ora por escrita colaborativa, ora por leituras interativas, ora pela liberdade de uso do senso criativo.

No que tange parte da investigação, os objetivos centram-se em analisar o uso do software Storybird, por crianças do $1^{\circ}$ ciclo, em contexto de educação formal por meio do ensino híbrido. Particularmente foi possivel observar os aspetos mais relevantes da utilização do computador em contexto de sala de aula, quanto ao domínio do software e hardware, traçar as dificuldades encontradas no processo, identificar avanços no campo cognitivo, quanto a contrução do pensamento crítico das 
crianças, aplicar a aprendizagem de modelo flex. Sobretudo explorar os resultados pertinentes a aquisição da leitura e escrita digital. A questão central leva a interrogar se houve e quais competencias foram alcançadas através dos contributos dos contos digitais exploradas na Storybird para o contexto de aprendizagem na sala de aula. Demais questões pertinentes trazem os pontos a destacar na análise de literacia digital. E ainda sobre o produto quanto à escrita digital, se o resultado foi positivo ou negativo se houve avanços cognitivos, se o metódo e ou modelo de ensino trouxe motivação à sala de aula.

O trabalho ancora-se em uma fundamentação da escola de Horn \& Staker, (2015) que traz como principal termo chave o ensino híbrido, defedem ser um programa de educação formal no qual um estudante aprende, pelo menos em parte, por meio de aprendizagem on-line, sobre o qual tem um tipo de controle em relaçao ao tempo, ao lugar, ao caminho e/ou ao ritmo e, pelo menos em parte, , em um lugar físico, supervisionado, longe de casa A prática ensino híbrido em alguns países até então, opor meio do modelo flex visa uma programa fluído, individualmente personalizado. Como característica fundamental temos o espaço físico, escola como indispensável e o professor fornece apoio presencial em uma base flexivel e adaptativa. As variações muito particulares são descritoras do modelo híbrido em uso.

\section{Das práticas de Lecto-escrita convencionais a hipertextuais}

Sob o plano de fundo da comunicação, Jakobson, (2008, p.:24) diz que uma das tarefas essenciais da linguagem é vencer o espaço, abolir a distância, criar uma continuidade espacial, encontrar e estabelecer uma linguagem comum 'através de ondas'. Unindo ao enfoque da construção do conhecimento, inspirada em produtos interativos e novos medias digitais é possível facilmente chegarmos ao viés escolar, bem como todos os caminhos que nos levam ao saber. Entretanto é dado certo que a medida que podemos contruir nossos conhecimentos podemos também desconstruir nossas habilidades. As crianças, que estão no centro desta abordagem, são genuínas em suas atitudes.

"Atualmente, um conceito muito utilizado é o que define competência como um conjunto de conhecimentos, habilidades e atitudes correlacionados que afetam parte considerável da atividade de alguém; se relaciona com o desempenho, pode ser medido segundo padrões preestabelecidos e pode ser melhorado por meio de formação e desenvolvimento" (Miranda, 2004 cit. por Borges e Oliveira, et al.2011).

Nesse contexto surge a cultura inserida no espaço digital, e é nesse prisma que iremos discutir a cibercultura. É do interesse de todos ver aflorar capacidades inerentes a autonomía do aluno. E a cultura dos médias tem papel relevante nessa caminhada. A discussão de especialista acerca de todo o meio envolvente e avanços é longa, mas pragmática. É preciso reeducar a escola para a cultura digital. Sobre o espaço digital discorre Santos, (2008), "a rede é a palavra de ordem do ciberespaço”. O próprio conceito de educação em rede só atinge o seu verdadeiro potencial quando este se encontra ao serviço da construção da aprendizagem como um processo de criação e inovação realizado colaborativamente. Considera Dias, 2008, que a mediação colaborativa constitui não só um processo de construção da interacção social entre os membros da comunidade, mas também a forma de realização da liderança partilhada dos processos de interacção no domínio da elaboração das aprendizagens no âmbito da rede" (Dias, 2008, p.:07)

Outro fator muito importante vivenciado nesse projeto de fundamental interesse para a discussão desse tema é abordado por Coutinho \& Bottentuit Junior, (2007) e cita que a definição mais comum encontrada para aprendizagem colaborativa é a situação na qual duas ou mais pessoas aprendem, ou tentam aprender em conjunto, algum conteúdo. A aprendizagem pode envolver um pequeno grupo, uma classe, uma comunidade com milhares de pessoas ou uma sociedade com centenas de milhares de pessoas.

Importa apresentar ainda o que entende Torres, Alcântara e Irala (2008, p.:7) por aprendizagem colaborativa o processo de reaculturação que ajuda os estudantes a se tornarem membros de comunidades de conhecimento cuja propriedade comum é diferente daquelas comunidades que já pertencem. Refere-se a uma passagem para outra cultura, para outro ambiente que possua outras normas, valores diferenciados daquele que nos encontramos.

Vale ressaltar que para ter domínio nessa comunidade de conhecimento se faz necessário estar inserido nesse processo de desenvolvimento e adquirir novas competências. Nessa perspetiva (Mazurkievicz, 2013, p.:55) diz que adotar como conceito de literacia digital as habilidades e estratégias que permitem utilizar as TIC de forma eficaz para identificar, localizar informações, avaliar criticamente a utilidade dessa informação, sintetizando as informações e então comunicar de forma correta essas informações.

$\mathrm{Na}$ busca por definições acerca da palavra letramento, como foi traduzida nos primeiros estudos sobre literacia digital no Brasil, Soares, (2010)

"afirma que etimologicamente a palavra literacy vem do latim e denota qualidade, condição, estado de ser. Ou seja: Literacy é o estado ou condição que assume aquele que aprende a ler e escrever. Implícita nesse contexto está a ideia que a escrita traz consequência socias, culturais, cognitivas e linguísticas." (Soares, 2010, p.:57)

Já Almeida e da Silva (2011, p.: 04) atribui características norteadoras sobre esta prática social e diz ser a "disseminação e uso de tecnologias digitais, marcadamente dos computadores e da internet que favoreceu o desenvolvimento de uma cultura de uso das mídias e, por conseguinte, de uma configuração social pautada num modelo digital de pensar, criar, produzir, comunicar, aprender - viver. E ainda reforça, ser as tecnologias móveis e a web 2.0, principalmente, responsáveis por grande parte dessa nova configuração social do mundo que se entrelaça com o espaço digital."

De acordo com Calixto e Maneira, (2015, p.:2) a dinâmica oferecida pelas inovações tecnológicas precisa 
estar inserida no ambiente escolar onde as crianças e adolescentes passam grande parte do dia. Todavia, e para tanto, a educação básica precisa passar por um período de reestruturação desse contexto, sendo levada a deixar a estagnação que a faz refutar os acontecimentos tecnológicos do presente.

Quanto as políticas públicas necessárias para que se torne presente o uso das TIC discorre Lourenço (2012, p.:17), que Portugal não é exceção, pelo que as escolas assistiram a uma melhoria de condições em relação ao acesso às TIC, tendo o Ministério da Educação renovado os equipamentos informáticos e equipado as escolas. De acordo com Viseu (2008), em 1997, em Portugal, 76\% por cento das escolas públicas não dispunham de computadores. Tornaram-se, desde então, uma área prioritária, para as quais foram definidas medidas a fim de suprir essas carências. Em seguida a autora diz que, os novos Programas de Português do Ensino Básico apresentam, parece consensual a necessidade de introduzir as tecnologias na escola mediante a criação de ambientes de aprendizagem apropriados, representando as tecnologias em Educação um poderoso meio que poderá ser aplicado ao "método científico das várias disciplinas ou áreas disciplinares que compõem o currículo". (p.42)

Entende-se que as práticas letivas orientadas pelo online é de grande alcance face a criação e partilha, mas se faz necessário fazer uso consciente para maior feedback da ferramenta, haja vista que a dinâmica dos hipertextos nos leva a ter o mundo em nossa tela. Em relação a esse modelo de sistema acrescenta Dias (2000, p. 149), o hipertexto educacional é uma rede de conceitos e relações análoga à rede semântica, pode então ser explorada e/ou construída não linearmente pelo aluno, de forma individual ou colaborativa, mas salientando sempre que é através do uso dos múltiplos percursos e lugares do leitor hipertexto que a não linearidade é construída. Nomeadamente ao hipermedia, Jonassen, (2000) considera ser simplesmente o casamento do multimédia com o hipertexto baseia-se no termo híper, que significa, acima, além, super, excessivo- mais do que normal. Complementa o referido autor a dizer que o hipertexto está para além do texto normal. Diz ser o texto normal linear e é construído de forma a ser lido do principio ao fim (Jonassen,2000, p.:23). Diante da nossa dinámica de leitura que vivenciamos no nosso dia a dia que isso já não se concebe com tanta frequência.

Vantagens do hipermédia enquanto ferramenta cognitiva de acordo com Jonassen (2000, p.:251)

- Os alunos estão muito mais empenhados cognitivamente no desenvolvimento de materiais do eu no seu estudo. A procura de informação promove uma aprendizagem mais significativa, sempre que os alunos planeiam publicar os seus produtos

- Aos alunos ficam altamente motivados pela atividade por serem donos do produto. Regra geral, ficam muito orgulhosos das suas produções.

As práticas de blended learning ou ensino híbrido da qual reflete-se essa investigação vem com a proposta de transformar a sala de aula para atender as necessidades de uma geração de alunos nativos digitais. $\mathrm{O}$ modelo insdustrial existente até hoje funcionou muito bem por longas décadas mesmo que por muitas vezes não se tenha ultrapassado a barreira do estudante ser um individuo, com capacidades cognitivas diferentes e niveis distintos de conhecimentos prévios, o que muitas vezes nos levou a pensar, o que eu estou a fazer aqui?, quando nada nos prendia a não ser a obrigação de lá estar. Nesse engate temos a certeza que a aprendizagem com foco no estudante a basear- se na valorização das competencias, é uma alternativa para rompermos esse ponto crítico esperienciado em escolas básicas.

A inovação desruptivo de ensino promovida por Horn \& Staker, (2015) apresenta o ensino híbrido como facilitador no processo de ensino-aprendizagem. Segundo os autores uma caracteristica importante dessa modalidade é que os estudantes desenvolvem um sentido de atuação e propriedade por seu progresso e subssequentemente, a capacidade de conduzir sua aprendizagem. (p.10) Ou seja, a esse modelo de aprendizagem dinamica em um mundo de mudanças constantes nos leva a crer que este desafio seja coeso e venha contemplar a urgência de beneficios no acto de aprender

\section{Metodologia}

Por este projeto ao que se aufere este artigo teve-se como problema a aquisição da leitura e escrita por meio de atividades praticadas em comunidades virtuais. Pensando na necessidade de observar as experiências individuais e coletivas nesse estudo de caso entendeu-se que este processo seria flexível, de caráter indutivo e descritivo, sendo assim o que melhor se ajustou a este estudo foi o paradigma qualitativo. Os dados foram recolhidos principalmente por observação empírica, evidências do contexto pedagógico, inferências cognitivas, participação, e atitudes apresentadas em atividades propostas. Recorremos a todo e qualquer vivencia nas redes sociais e no contexto de aprendizagem letiva. Haja vista a dedicação e interesse dos envolvidos no comprimento das atividades, foi levado a cabo o registo com o diário de bordo, com os áudios, conversas com a professora, fotos, vídeos, diálogos e comentários em rede, opinião da professora, pais e finalmente recorreu-se a e imagens do processo de produção e interação salvas na ferramenta.

De acordo com (Creswell, 2012) os pesquisadores qualitativos procuram entender o ambiente dos participantes visitando esse contexto e colhendo pessoalmente. Continua seu pensamento a dizer que o processo de pesquisa qualitativo é bastante indutivo, com o pesquisador gerando significado a partir dos dados coletados no campo. E quanto a técnica dessa pesquisa, o referido autor considera que o investigador sempre faz alegações de conhecimento com base principalmente ou em perspetivas construtivistas (ou seja, significados múltiplos das experiências individuais, significados social e historicamente construídos, com objetivo de desenvolver uma teoria ou um padrão) ou em perspetivas reivindicatórias/participatórias, ou em ambas (Creswell, 2010).

A categorização foi ancorada no principio da pertinência que segundo Esteves, (2006 p.:122) 
"significa que o sistema de categorias criado é defensável à luz das questões de investigação e que cada categoria tem sentido face ao material empírico e / ou ao quadro teórico de partida, se este existe”. Essa pesquisa foi realizada em um centro escolar da região do Minho, em uma sala de $1^{\circ}$ ciclo, e contou com a participação de 14 alunos, com a supervisão do diretor e colaboração da professora titular. Foi aplicada no âmbito da disciplina de Língua Portuguesa, e pode ser flexibilizada no currículo por diferentes áreas do conhecimento. Quanto ao quadro descritivo, o contexto de realização iniciou-se com a troca de sala, pois os alunos foram direcionados a sala da biblioteca por ser o local que traz os computadores para o uso das crianças em atividades complementares. Durante três dias na semana as crianças permaneceram por uma hora nesta sala onde acederam ao amibiente virtual de aprendizagem. Inicialmente foram orientadas quanto a introdução ao uso do computador, depois as crianças foram incumbidas de aceder a página Storybird, realizarem a tarefa apresentada em seu espaço virtual, e desenvolverem a atividade que consistia em realizar a produção de um conto de 10 páginas contendo ilustrações de escolha livre, dentro da temática e apresentar ao fim do projeto o livro impresso em um dia de autógrafos com a presença dos pais e divulgação do material virtual via Facebook e como material extra foi criado um vídeo com o relato de todos que também foi divulgado em redes sociais a contar principalmente com a participação dos pais. $\mathrm{O}$ veículo que os transportou a essa experiência foi o fio condutor do nosso trabalho. Vale ressaltar o que pode definir o Storybird. Trata-se de uma ferramenta online que permite a criação de histórias de forma individual ou colaborativa. Pode-se criar uma turma online para a produção das histórias de forma bem simples e organizada, facilitando a participação de todos na construção da história. À medida que escolhemos nosso modelo dentre os que lá estão estabelecidos, podemos criar nossa sequência narrativa, alterar, mexer e refazer sozinhos ou em colaboração com quem for convidado. Desde que estejamos inscritos, é possível publicar, guardar em sua biblioteca e/ou compartilhar por e-mail com amigos e familiares, e dessa forma, nos tornamos, protagonistas de nossa história digital.

\section{Resultados iniciais}

A análise preliminar que foi retirada desse estudo incide sobre à inclusão digital que por sua vez alcançada concebe o conhecimento por multimeios ou ferramentas de aprendizagem digital a serem usados em computadores ou demais dispositivos ligados a rede seja em ambiente formal em contexto curricular transversal (escola) ou na interação com os pais em casa e colegas (casa). O estudo sustenta a ideia que é possível motivar o aluno a criação de histórias (contos infantis) dado o envolvimento no processo e resultado do produto.

"De certa forma, a arte de contar histórias foi sempre utilizada nas tecnologias mais recentes. Algumas pessoas declaram que as pinturas nas cavernas e outros achados antigos eram por vezes utilizados para contar histórias. Pode parecer difícil pensar em desenhos pré-históricos em paredes de grutas como uma forma de tecnologia, mas no início da civilização humana eram exatamente isso" (Czarnecki, 2009).

Quanto aos benefícios, na construção do pensamento crítico, foi percetível haja visto a rápida construção do imaginário e a tentativa de melhorias nos argumentos ou organização de ideias. Relativamente ao domínio do software e hardware o estudo evidenciou a maior conquista encontrada o que merece um maior destaque nesse contexto por ter mostrado ultrapassar limitações genuínas por ser uma experiência jamais utilizada pela maioria dos alunos, e que por sua vez refletem na resposta operacional que poderia ter precisado de uma demanda maior de tempo, por ainda não estarem habilitados ao uso da máquina e do software mas não foi o que aconteceu.

Como apresentado no quadro dos resultados dado o diagnóstico inicial que a maioria das crianças não faziam uso do computador na escola e uma minoria fazia uso em casa nos computadores dos pais ou tabletes particulares assim como apresenta-se abaixo no gráfico 1, dos conhecimentos prévios, observou-se que as crianças que nunca tiveram contacto com o computador representam a maioria com $64 \%$, o que mostram evidências que os alunos adquiriram competências digitais dentro do que foi proposto.

\section{CONHECIMENTO PRÉVIO}

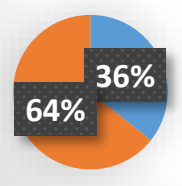

- Alunos que já tiveram algum contacto com o computador

Gráfico 1 - Categoria a representar o conhecimento que o aluno já trazia antes da investigação.

As análises do gráfico 2 quanto ao desenvolvimento do pensamento crítico e no processo de literacia digital considerou positivo e negativo como valores qualitativos e considerou algumas questões para chegar a este resultado e evidenciou-se que apenas $7 \%$ dos alunos não agiram com senso crítico em suas produções.

\section{PENSAMENTO CRÍTICO}

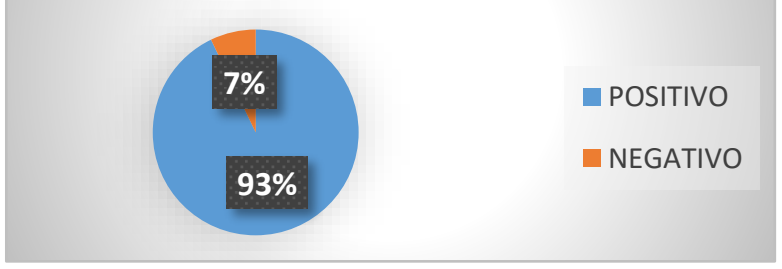

Gráfico 2- Categoria a representar o pensamento crítico

Quanto ao gráfico 3, foi levado em conta a evolução, desde o inicio das atividades até a culminância da investigação. Contudo, avaliou-se a atitude do aluno nas escolhas das imagens, na organização das ideias, no 
senso imaginativo no momento da escolha das ilustrações e criação do conto digital. Discorre sobre essa ideia, Jonassen (2000, p.:225) "As ferramentas de representação visual podem ajudar os alunos a compreenderem e a expressarem ideias que, de outra forma, não seria possível. São ferramentas que representam visualmente ideias abstratas, possibilitando aos alunos a utilização do seu sentido mais desenvolvido." Os resultados reforça a possibilidade de desenvolver pensamento crítico na escola através do trabalho colaborativo em rede.

Em seguida e como último quadro apresentado nessa breve descrição de resultados foi analisado quando ao uso em rede a evolução dos alunos na escrita digital, no domínio do software, no domínio do hardware, na interação online. Dentro do que foi proposto quadro 3 mostra avanços cognitivos e alterações nas práticas dos sujeitos em todas as questões exploradas.

\section{ANÁLISE DO PROCESSO DE LITERACIA DIGITAL}

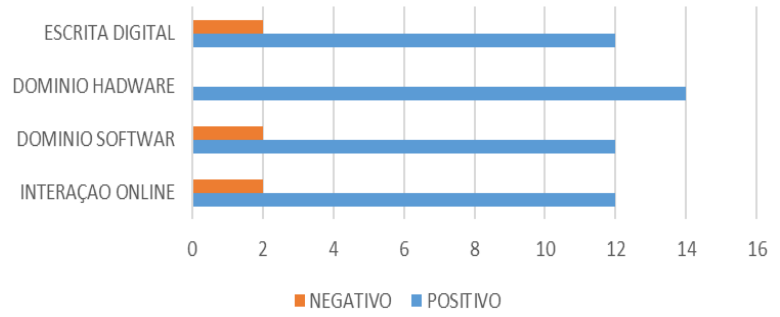

Gráfico 3 - Categorias da análise do processo de literacia digital.

\section{Considerações finais}

Depreende-se que esses alunos apresentaram progressos no quesito, literacia digital, dentro do que foi proposto neste período de investigação. Hoje já demonstram novas competências com aproveitamento em ambiente formal e informal. Portanto é pertinente acrescentar que este foi um cenário oportuno ao aprimoramento das práticas sociais de aprendizagens das tecnologias digitais com ênfase nas abordagens colaborativas, que se deu por meio de ferramentas educativas on line em ambiente hibrido de aprendizagem. Ainda como contributo acrescenta-se um movimento dinâmico da criatividade percebida nomeadamente no produto final obtido na ferramenta cognitiva, sobretudo a resposabilidade do aluno que evidenciasse frente ao seu protagonismo exercido nesse programa de ensino. Nas perceções negativas pode-se apontar que problemas relacionados a incipiente distribuição de pontos de conexão de rede (internet) atrapalham o trabalho de profissionais empenhados em promover a inclusão digital, percebe-se sobretudo uma certa precariedade ao acesso a internet em zonas mais distante dos meios urbanos. Contudo sabemos que a aplicaçao de projetos esporáticos, ou viabilizar pontualmente uma disciplina enriquecida de tecnologia, nao irá atender a urgência da demanda, que necessita de rápidas mudanças curriculares e estruturais nas escolas básicas. Partindo das informações coletadas e dos materiais multimédias utilizados na construção desse conhecimento e observação dos sujeitos em análises das práticas de aprendizagem proposta, percebeu-se que os incentivos por parte das políticas públicas em relação à infraestrutura ja mencionadas, suporte tecnológico, capacitação técnica e currículo, vêem a ser insuficientes. No entanto, os resultados, mostram que a utilização das ferramentas da web em ambiente colaborativo com base em modelos disruptivos de educação formal, juntamente com o conhecimento adquirido por alunos do $1^{\circ}$ ciclo, pode fomentar o uso consciente do computador na obtenção de aprendizagens significativas em diferentes situações comunicativas. Temos assim, que o trabalho com a produção dos contos digitais em sala de aula, auferem um ambiente criativo tanto no contexto físico como virtual dos quais foram vivenciados na escola. Como contributo, este trabalho espera estar inserido nos estudos que norteiam a comunidade científica e que preconizam transformações pertinentes na usabilidade pedagógica das instituições

\section{Referências}

Almeida, M. E. B., \& da Silva, M. D. G. M. (2011). Currículo, tecnologia e cultura digital: espaços e tempos de web currículo. Revista Científica ecurriculum. ISSN 1809-3876, 7(1). Acesso em http://revistas.pucsp.br/index.php/curriculum/article/v iew/5676/4002

Araújo, V. D. L., \& Glotz, R. E. O. (2009). O Letramento digital enquanto instrumento de inclusão social e democratização do conhecimento: desafios atuais. Revista Paidéi. Disponível em: http://revistapaideia.unimesvirtual.com.br/index.php?j ournal=paideia $\&$ page $=$ article $\&$ op $=$ view $\&$ path []$=85 \&$ path[]=50 Acesso [ 05.10.2015]

Bottentuit Junior, J. B., \& Coutinho, C. P. (2007). A Educação a Distância para a Formação ao Longo da Vida na Sociedade do Conhecimento. Disponível em http://hdl.handle.net/1822/497. Acesso [12.02.2016] .

Creswell, J. W. (2010). Projeto de pesquisa métodos qualitativo, quantitativo e misto. In Projeto de pesquisa métodos qualitativo, quantitativo e misto. Artmed.

Dias, P. (2000). Hipertexto, hipermédia e media do conhecimento: representação distribuída e aprendizagens flexíveis e colaborativas na Web. 145149. Disponível em http://hdl.handle.net/1822/497. Acesso [12.01.2015]

Dos Santos Calixto, A. V., \& Maneira, S. (2015). A corresponsabilidade na construção do conhecimento: inversão do protagonismo na educação. Revista de Estudios e Investigación en Psicología y Educación, (13), 038-042. http://revistas.udc.es/index.php/reipe/article/view/295. Acesso em [05.10.2015

Dos Recursos Educativos, Observatório. O. (2014). Por uma utilização criteriosa dos recursos digitais em contextos educativos. Um balanço de investigações recentes. em: 
www.ore.org.pt/.../EstudoORE_RecursosDigitaisemC ontextosEducativos. Acesso [17.02.2015]

Falkembach, G. A. M. (2005). Concepção e desenvolvimento de material educativo digital. RENOTE, 3(1). Disponível em seer.ufrgs.br/renote/article/download/13742/7970.

Acesso [16.02.2015]

Horn, M. B., \& Staker, H. (2015). Blended: Usando a inovação disruptiva para aprimorar a educação (M. C. G. Monteiro, Trans.). Porto Alegre: Penso.

Lima, J. Á., \& Pacheco, J. A. (2006). Fazer investigação: contributos para a elaboração dissertações e teses. Porto: Porto Editora. 105-125

Lourenço, M. C. T. A. D. (2012). Da narrativa a narrativa digital: o texto multimodal no estudo da narrativa. Disponível em http://hdl.handle.net/1822/23658. Acesso em 22/03/2016

Mazurkievicz, G. L. (2013). Educação a distância e a literacia digital no processo de formação continuada de professores. Disponível em https://repositorio.ufsc.br/handle/123456789/107595 . Acesso [17.02.2015]

Ramos, A., \& Faria, P. (2012). Literacia digital e literacia informacional: breve análise dos conceitos a partir de uma revisão sistemática de literatura. Linhas, 13(2), 29-50. Disponível em: http://www.revistas.udesc.br/index.php/linhas/article/ view/2970. Acesso [17.02.2015]

Santos, A. (2008). Complexidade e transdisciplinaridade em educação: cinco princípios para resgatar o elo perdido. Revista Brasileira de Educação, 13(37), 7183. Disponível em: http://www.scielo.br/pdf/rbedu/v13n37/07.pdf/ Acesso [ 16.02.2015]

Silva, B. D. D. (2001). A tecnologia é uma estratégia. Disponível em http://hdl.handle.net/1822/17940 Acesso [12.01.2015]

Soares, M. (2002). Novas práticas de leitura e escrita: letramento na cibercultura. Educação e Sociedade, 23(81), 143-160.

Storybird disponível em : http://storybird.com Acesso [02.06.2015]

Torres, P. L., Alcantara, P. R., \& Irala, E. A. F. (2004). Grupos de consenso: uma proposta de aprendizagem colaborativa para o processo de ensino-aprendizagem. Revista diálogo educacional, 4(13), 129- 